\title{
Determination of the Response of Some Cotton Varieties to Cotton Wilt Disease Caused by Verticillium dahliae Kleb ${ }^{\#}$
}

\author{
Sadettin Çelik ${ }^{1}$, Adem Bardak², Oktay Erdoğan ${ }^{3 *}$, Döne Parlak², Rıdvan Uçar², \\ Halil Tekerek $^{2}$, Ali Can Sever ${ }^{2}$, Khizer Bahatti Hayat ${ }^{2}$
}

${ }^{1}$ Department of Agricultural Biotechnology, Faculty of Agriculture, Bingol University, 12000 Bingol, Turkey

${ }^{2}$ Department of Agricultural Biotechnology, Faculty of Agriculture, Kahramanmaraş Sütçü İmam University, 46100 Kahramanmaraş, Turkey

${ }^{3}$ Department of Biosystem Engineering, Faculty of Engineering-Architecture, Nevşehir Hacı Bektaş Veli University, 50300 Nevşehir, Turkey

A R T I C L E I N F O
\#This paper was presented at the International
Conference on Agriculture, Forest, Food
Sciences and Technologies (15-17 May 2017,
Turkey).

Research Article

Received 18 August 2017

Accepted 12 October 2017

Keywords:

Cotton

Verticillium wilt

Resistance

Disease severity

Pathotype

*Corresponding Author:

E-mail: oktaye@gmail.com

\begin{abstract}
A B S T R A C T
Verticillium Wilt Disease is one of the most important diseases affecting the rate of cotton yield. There is no economic chemical control for Verticillium wilt, but it is recommended to use resistant varieties to control this disease. This experiment was carried out in a randomized plot design with four replications in the growth chamber to determine the response of some cotton cultivars against a defoliating and non-defoliating pathotypes of Verticillium dahliae Kleb. In the study, a total of twenty cotton cultivars i.e. the resistant control GIZA 75, the tolerant control CARMEN and the susceptible control ACALA SJ2, defoliating (PYDV6 isolate) and non-defoliating (Vd 11 isolate) pathotypes were used, and cotton varieties were tested using conidial suspension technique. Analysis of variance showed significantly $(\mathrm{P}<0.05)$ differences among cotton cultivars. The lowest disease severity for the defoliating pathotype was determined in the resistant control GIZA 75 (1.00), followed by the tolerant control CARMEN (1.75) and FAMOSA (1.87). The highest disease severity was determined in the susceptible control ACALA SJ2 by 3.50 and BEREN by 3.12. The lowest disease severity for the nondefoliating pathotype was again determined in the resistant control GIZA 75 by 0.35 , followed by the tolerant control CARMEN and GAIA. The highest disease severity value was again found in the susceptible control ACALA SJ2 by 2.50 followed by BEREN 2.12. As a result, cotton cvs FAMOSA and GAIA were tolerant to Verticillium wilt and BEREN was found to be susceptible.
\end{abstract}

DOI: https://doi.org/10.24925/turjaf.v5i12.1488-1492.1476

\section{Introduction}

Cotton (Gossypium spp.) is an industrial crop cultivated in nearly 70 countries as the means of living for 180 million people. Its natural fiber, the oil obtained from its seeds, and other by-products make it become an economically important plant (Akçar, 1986). The cotton plant provides raw material for more than 50 industrial branches with its fibers that contain $94-96 \%$ cellulose and seeds that have $17-24 \%$ fat.

Cotton is cultivated in 30.085 .000 ha area mostly in Asia, and then in America and Africa, and a total of 22.480.000 tons fiber cotton are produced all over the world (USDA, 2016). In our country, cotton is cultivated in 416.000 ha area in for main regions, Southeastern Anatolia, Aegean, Çukurova and Antalya. A total of 756.000 tons of cotton fiber yield is produced in this regions (Anonymous, 2017). Turkey ranks the $7^{\text {th }}$ in the world with $2.5 \%$ (USDA, 2016).
There are many factors limiting the production of cotton cultivation. One of these factors is the Verticillium wilt caused by Verticillium dahliae Kleb. The pathogen may cause wilt in more than 400 plant species with a series of host plants like vegetables, ornamental plants, legumes, industrial plants, fruit trees and weeds (Joaquim and Rowe, 1990).

In our country, the losses in cotton cultivation due to Verticillium wilt are detected in Izmir, Aydın and Manisa with $12 \%$, in Adana with $12 \%$, and in Antalya with $4 \%$ (Esentepe, 1974; Sezgin, 1985; Sağır et al., 1995; Çelik et al., 2010). In the world, annual losses in cotton cultivation due to Verticillium wilt were reported as 1.5 million bales (Nemli, 2003). Meanwhile, it has been reported in several studies that these losses might be reduced by selecting very susceptible cultivars, and using the resistant cultivars that have high-level performance (Bell, 2001). 
Verticillium spp. invades the xylem and cause obstruction in it, thus causing great damage in the plant in terms of yield and quality (Beckman, 1987; Tjamos et al., 2000; Pegg and Brady, 2002). It is already known that the disease factor sustains its life in soil with the help of its microsclerotia even in unfavorable conditions, and may stay alive in soil more than 20 years (Isaac, 1967). The pathogen enters the roots of the plant, proceeds to external cortical layer, invades endodermis and then carried through transpiration and causes obstruction in xylem vessels (Rowe and Powelson, 2002). The symptoms of wilt start from the lower leaves, and partial drying sections and shrivels are observed. If the seeds are planted late, or if the disease starts early, the height of the plant remains short, the number of the boll decrease, the already-formed bolls remain small, and finally, the plant dies (Agrios, 2005). Due to the disease, the percentage of unripen fibers increases, fiber quality parameters such as fiber length and fiber strength decrases, and seed weight and seed vitality also reduce (Watkins, 1981).

In the control of Verticillium wilt, crop rotation, balanced fertilization, and irrigation, and weed control as well as the development of resistant cultivars have been basic approaches. One of the most effective methods for controlling a disease that does not have an economic chemical control is reported as the use of resistant cultivars (Onan and Karcilığlu, 1998).

In a study, was conducted to determine the reactions of cotton cultivars against both pathotypes of $V$. dahliae, it was determined that the cvs Deltapine 15/21, Maraş 92, Sayar 314 and Erşan 92 cultivars were very susceptible to T-1 race; cv Deltapine 15/21 was very susceptible to SS-4 race; Acala cultivars were resistant at a moderately; standard cv Çukurova 1518 was very susceptible to both races; cvs Giza 45, Giza 75 and Aşkabat were resistant to $\mathrm{T}-1$ race in field conditions; and all the other cultivars except DPL 15/21, Çukurova 1518 and Sayar 314 were moderately or highly resistant to SS-4 race (Kurt and Biçici, 1998). In the study conducted in the greenhouse conditions with 5 cotton genotypes, cotton genotypes showed susceptible to Verticillium wilt at different levels (Corato et al., 2000). In a study carried out to determine the susceptibility of cotton cultivars to Verticillium wilt Göre et al. (2004) reported that the susceptible ones were more common than the tolerant ones; and the Carmen, $\mathrm{N}$ 84-S, STG-14 and NDT-11 genotypes showed tolerant reaction to the disease, and the remaining genotypes were susceptible or very susceptible to the disease. Korkmaz (2005), conducted a study with 10 cotton cultivars between 2002-2005 years in Kahramanmaraş, and reported that Erşan 92, Maraş 92, Sayar 314, Stoneville 453 and Golda cultivars were resistant to the Verticillium wilt; Teks and Carmen cultivars were tolerant; cvs Çukurova 1518, Karlık and Aktaş 3 were susceptible. Galbieri et al. (2008), examined 25 cotton genotypes in the greenhouse conditions in terms of resistance against Verticillium wilt, and reported that the majority of genotypes had different resistance levels. Gözcü et al. (2012), conducted a study on 13 cotton cultivars in Kahramanmaraş in 2009-2010 years, and determined that cv Teks was the most tolerant; and the GSN-12, St-468, Ayhan 107 and BA 525 cultivars as tolerant ones. Karademir et al. (2012), performed a study to determine the reactions of 10 different cotton cultivars commonly grown in Diyarbakır against Verticillium wilt, and found that cvs Teks, Golda and Carmen were tolerant in terms of the disease severity in the leaves and stems, and Maraş 92, Sayar 314 and St-453 cultivars were susceptible. Erdoğan and Kurt (2013), conducted a study to determine the susceptibility of some cotton cultivars to both pathotypes of $V$. dahliae in cotton plants which received PYDV6 and Vd11 isolates, and determined that the lowest disease severity was in tolerant control Giza 45 and the highest disease severity in susceptible control Albania 61-72.

The aim of the study was to determine the reactions of new cotton cultivars with high yield and fiber quality properties in our country against the defoliating and nondefoliating pathotypes of Verticillium Wil Disease under the growth chamber conditions.

\section{Materials and Methods}

Cotton genotypes and $V$. dahliae isolates

17 cotton cultivars growing in our country (Harem, 2014), and a total of 20 cotton cultivars such as resistant GIZA 75 (Kurt and Biçici, 1998), tolerant CARMEN (Erdoğan et al., 2006) and susceptible ACALA SJ2 (Erdoğan et al., 2014) cultivars against Verticillium wilt included in the study (Table 1). In pathogen inoculations, the Vd11 (non-defoliating pathotype) and PYDV6 (defoliating pathotype) isolates of $V$. dahliae isolated from cotton and known for virulence level were used in the study (Erdoğan, 2009).

Table 1 Species and origins of cotton cultivars in the experiment

\begin{tabular}{l|ll}
\hline Cultivar & Species & Origin \\
\hline ACALA SJ2 & Gossypium hirsutum & USA \\
ADN 811 & Gossypium hirsutum & TURKEY \\
AKSEL & Gossypium hirsutum & TURKEY \\
BEREN & Gossypium hirsutum & TURKEY \\
CARISMA & Gossypium hirsutum & TURKEY \\
CARMEN ${ }^{2}$ & Gossypium hirsutum & AUSTRALIA \\
DICLE 2002 & Gossypium hirsutum & TURKEY \\
DP 419 & Gossypium hirsutum & USA \\
FAMOSA & Gossypium hirsutum & USA \\
GAIA & Gossypium hirsutum & USA \\
GIZA 75 & Gosyypium barbadense & EGYPT \\
LYDIA & Gossypium hirsutum & TURKEY \\
NATA & Gossypium hirsutum & USA \\
ÖZKAN & Gossypium hirsutum & TURKEY \\
PG 2018 & Gossypium hirsutum & TURKEY \\
PRIMERA & Gossypium hirsutum & AUSTRALIA \\
SG 501 & Gossypium hirsutum & USA \\
ST 474 & Gossypium hirsutum & USA \\
STV 373 & Gossypium hirsutum & USA \\
UGUR & Gossypium hirsutum & TURKEY \\
\hline
\end{tabular}

${ }^{1}$ Susceptible-control, ${ }^{2}$ Tolerant-control, ${ }^{3}$ Resistant-control

\section{Pathogen inoculations}

In pot trials, the susceptibility of cotton cultivars to $V$. dahliae was determined with conidial suspension technique. The experiment was carried out in a randomized plot design with four replications in the growth chamber (at $24 \pm 1^{\circ} \mathrm{C}, 12 \mathrm{~h}$ light $/ 12 \mathrm{~h}$ dark cycle). 
For this purpose, mixture of equal parts of soil, sand, and turf were sterilized at $121^{\circ} \mathrm{C}$ for one hour, filled in plastic pots $(5 \mathrm{~cm}$ in diameter) and 4 seeds were planted in each pot. When the seedlings were at cotyledon leave period, one plant was left in each pot. For inoculation, 2-weekold culture of $V$. dahliae isolates (Vd11 and PYDV6) being highly virulent which were grown in Potato Dextrose (Difco) broth medium were used. After a certain amount of water was added to the $V$. dahliae cultures, fungal conidia was transferred to the water from the agar surface with a sterile spatula; and spore suspension was filtered with 2 layers of sterile cheesecloth to remove the mycelium and agar particles. Five $\mathrm{ml}$ of spore suspension adjusted to $4 \times 10^{6}$ spores $\mathrm{ml}^{-1}$ with the help of haemocytometer was poured to the bottom parts of each plastic pot. Control plants were treated similarly with sterile distilled water. Then, the plants that were in 4-6leave period were transferred into the pots treated with $V$. dahliae inoculum.

\section{Disease evaluation}

Inoculated and control cotton plants were assessed based on the progression of the disease nearly 3-5 weeks later after inoculation using a scale of 0 to 5 (Tsror et al., 2001) (Tablo 2). Disease Severity Index (DSI) was calculated using the formula and data obtained from the experiment were subjected to Arcsin for transformation (Karman, 1971).

$$
\text { DSI }=[(a \times 0)+(b \times 1)+(c \times 2)+(d \times 3)+(e \times 4)+(f \times 5)] / M
$$

DSI :Disease severity index; a, b, c, d, e, f: The plant number with degree $0,1,2,3,4,5$ respectively,

M :Total plant number.

\section{Statistical analysis}

All data obtained in the experiments were analysed statistically by using JMP statistical software program (5.0.1, SAS Institute, Cary, NC) for analysis of variance and means were compared using Fisher's protected least significance difference (LSD) test at 5\% probability level (Steel et al., 1997).

Table 2 The 0-5 scale used in determining the reaction of the cotton cultivars against Verticillium Wilt

\begin{tabular}{ll}
\hline SV & Disease symptoms \\
\hline 0 & No symptoms \\
1 & Chlorosis in lower leaves \\
2 & Moderate (30-50\% of leaves) wilt with severe chlorosis \\
3 & Moderate wilt and necrosis \\
4 & Severe (more than $50 \%$ of leaves) wilt and necrosis \\
5 & Dead plant \\
\hline SV: Scale Value
\end{tabular}

\section{Results and Discussion}

The mean disease severity values obtained from the pot trial of the cotton cultivars in the growth chamber are given in Table 3 . In the statistical analysis made in the leaves in terms of disease severity, the difference between the cultivars was found to be significant $(\mathrm{P}<0.05)$. The disease severity values of the PYDV6 (defoliating pathotype) isolate in the leaves were found to be higher than those of the Vd11 (no-defoliating pathotype) isolate (Table 3). The authors of the study interpreted this situation with high virulence, the lack of resistant cultivars, fast progression of the infection, and the plant's losing its leaves that did not have any symptoms in a very fast way after the infection (Daayf et al., 1995; Korolev et al., 2001; Zhengjun et al., 1998). Wu and Wu (1997) reported that the defoliating races of the pathogen were the most virulent races, and these races limited cotton production all over the world. In previously conducted studies, it has been reported that cotton cultivars showed susceptibility to both pathotypes of $V$. dahliae at different levels. In result, most of the cultivars were very susceptible to defoliating pathotype in the growth chamber conditions, and the cv Carmen was resistance to both pathotypes at different levels (Göre et al., 2009; Erdoğan and Kurt, 2013; Erdoğan et al., 2014; Erdoğan et al., 2015).

In the pot trial, in terms of disease severity values in the leaves, in the cotton cultivars with Vd11 isolate, the lowest disease severity average value was determined in the resistant control GIZA $75(0.35)$, followed by the tolerant control CARMEN (1.37) and GAIA (1.37). The highest mean disease severity value was detected in susceptible control ACALA SJ2 by 2.50, and in BEREN by 2.12 . The average lowest disease severity value in the PYDV6 isolate belonging defoliating pathotype was detected in again in resistant control GIZA 75 (1.00), followed by tolerant control CARMEN (1.75) and FAMOSA (1.87). The average highest disease severity value was detected again in susceptible control ACALA SJ2 (3.50) and in BEREN (3.12). In terms of mean disease severity values, the results determined in FAMOSA, GAIA and PG 2018 cotton cultivars were measured to be close to resistant and tolerant control varieties against both pathotypes (Table 3). Galanopoulo (2006), reported that the cotton cultivars of G. hirsutum species were not immune fully, and these cultivars showed different resistance to the Verticillium wilt disease. Bölek et al. (2011), conducted a study in the growth chamber to determine the susceptibility levels of cotton genotypes to defoliating pathotype of $V$. dahliae, and reported that the difference between the genotypes was significant $(\mathrm{P}<0.01)$, and the most tolerant cultivar was Carmen and the most susceptible cultivar was Çukurova 1518. Erdoğan and Kurt (2013), conducted a study to determine the reactions of 21 cotton cultivars cultivated commonly in our country against defoliating and non-defoliating pathotypes of the pathogen in the growth chamber conditions. Finally, it was determined that the lowest disease severity against both pathotypes of $V$. dahliae was detected in resistant control Giza 45 followed by Julia, St-373, Fibermax 819 and Gloria. Erdoğan et al. (2014), reported that the lowest disease severity values to both pathogens were detected in Giza 45 in conidial suspension technique, these values were higher in the stem injection method, and the highest disease severity values in stem injection method was detected in Acala SJ2 and Çukurova 1518 cultivars. Erdoğan et al. (2015), determined the susceptibility of 13 cotton genotypes developed by breeding against Verticillium wilt, and the lowest disease severity value was detected in tolerant control Carmen in the growth 
chamber conditions against both pathotypes, and the highest disease severity was detected in susceptible control Çukurova 1518. Göre et al. (2017), conducted a study to determine the reactions of 10 genotypes of different Gossypium spp. against both pathotypes of the pathogen in the growth chamber and determined that the lowest disease severity values were in Maydos Yerlisi ( $G$. herbaceum L.) cv, and reported that Carmen cv gave values that were similar to this. Akkose Baytar et al. (2017), conducted a study to determine the resistance alleles and molecular diversity for Verticillium wilt in elite cotton cultivars and reported that Carmen and Prestige cultivars were the most tolerant genotypes; and Nazilli 87, Nazilli M503/2, DPL SR 383, BA 308 and PG 2018 genotypes had close values with Carmen and Prestige genotypes.

Table 3 The average values of disease severity for cotton cultivars in pot trials

\begin{tabular}{|c|c|c|}
\hline \multirow{2}{*}{ Cultivar } & \multicolumn{2}{|c|}{ Disease severity values in pot trials } \\
\hline & Vd11 isolate & PYDV6 isolate \\
\hline ACALA SJ $2^{1}$ & $2.50^{\mathrm{a}}$ & $3.50^{\mathrm{a}}$ \\
\hline ADN 811 & $1.87^{b c}$ & $2.37^{b c}$ \\
\hline AKSEL & $1.87^{\mathrm{bc}}$ & $2.50^{\mathrm{b}}$ \\
\hline BEREN & $2.12^{b}$ & $3.12^{\mathrm{a}}$ \\
\hline CARISMA & $1.87^{b c}$ & $2.25^{\mathrm{bd}}$ \\
\hline CARMEN $^{2}$ & $1.37^{\mathrm{e}}$ & $1.75^{\mathrm{e}}$ \\
\hline DICLE 2002 & $1.62^{\mathrm{ce}}$ & $2.12 \mathrm{bd}$ \\
\hline DP 419 & 1.62 ce & $2.37 \mathrm{bc}$ \\
\hline FAMOSA & 1.50 de & $1.87 \mathrm{de}$ \\
\hline GAIA & $1.37^{\mathrm{e}}$ & $2.00^{\mathrm{cd}}$ \\
\hline GIZA $75^{3}$ & $0.35^{\mathrm{f}}$ & $1.00^{f}$ \\
\hline LYDIA & $1.62^{\mathrm{ce}}$ & $2.25^{\mathrm{bd}}$ \\
\hline NATA & $1.62^{\mathrm{ce}}$ & $2.37 \mathrm{bc}$ \\
\hline ÖZKAN & $1.75^{\mathrm{cd}}$ & $2.37 \mathrm{bc}$ \\
\hline PG 2018 & $1.50 \mathrm{de}$ & $2.00^{\mathrm{cd}}$ \\
\hline PRIMERA & $1.75^{\mathrm{cd}}$ & $2.12^{b d}$ \\
\hline SG 501 & 1.62 ce & $2.25 \mathrm{bd}$ \\
\hline ST 474 & 1.62 ce & $2.37^{b c}$ \\
\hline STV 373 & $1.50^{\mathrm{de}}$ & $2.25^{\mathrm{bd}}$ \\
\hline UĞUR & $1.87^{b c}$ & $2.37^{b c}$ \\
\hline Mean & 2.26 & 1.64 \\
\hline $\mathrm{F}_{\text {cultivar }}$ & 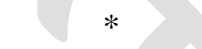 & 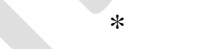 \\
\hline $\mathrm{CV}_{(\%)}$ & 13.07 & 15.81 \\
\hline
\end{tabular}

${ }^{1}$ Susceptible-control, ${ }^{2}$ Tolerant-control, ${ }^{3}$ Resistant-control, *Different letters between genotypes denote significant differences (LSD test, $\mathrm{P}<0.05)$

\section{Conclusion}

Verticillium wilt is a disease observed in areas where cotton is cultivated and does not have an economical chemical control method. This disease limits the cotton yield at a great rate all over the world. The defoliating and non-defoliating pathotypes of this disease are observed in our country. The defoliating pathotype of the pathogen is more virulent and more destructive when compared with the non-defoliating pathotype. One of the effective methods in the control of Verticillium wilt is to use resistant cotton cultivars. For this reason, it is important to determine the susceptibility levels of the cotton cultivars cultivated commonly in our country to the two pathotypes of $V$. dahliae. In the present study, pot trials were conducted with FAMOSA, GAIA and PG 2018 cotton cultivars in the growth chamber against two pathotypes in terms of average disease severity values, and resistant control GIZA 75 and tolerant control CARMEN have close values and were found as promising. However, it is necessary to establish another trial with the same cotton cultivars used in the study in a field that is infected naturally, and the performances of these cultivars in terms of resistance to the disease and yield and fiber quality must be determined. As a result of the present study, the cultivars determined to be tolerant to Verticillium Wilt Disease may be used as parent cultivars by breeders in cotton resistance breeding programs.

\section{Acknowledgements}

We would like to thank TUBITAK (Project number: 2140087) for their financial support and Prof Dr. Kemal Benlioğlu (Adnan Menderes University, Faculty of Agriculture, Aydın, Turkey) for kindly providing PYDV6 isolate.

\section{Authors' Contributions}

This study is a part of the Sadettin Çelik's postgraduate thesis. Adem Bardak and Oktay Erdoğan are a supervisor.

\section{References}

Agrios GN. 2005. Plant Pathology. 5th Edition, Elsevier Acad. Press, $163-164 \mathrm{p}$.

Akçar H. 1986. A Research on the Effect of Different Sowing Shapes on Yield and Yield Components of Two Cotton Varieties (Gossypium sp.) in Cukurova Conditions. MSc Thesis, Çukurova University, Graduate School of Natural and Applied Sciences, Field Crops Department, Adana. (in Turkish with English abstract)

Akkose Baytar A, Erdogan O, Frary A, Frary A, Doganlar S. 2017. Molecular Diversity and Identification of Alleles for Verticillium Wilt Resistance in Elite Cotton (Gossypium hirsutum L.) germplasm. Euphytica, 213: 31.

Anonymous. 2017. Turkish Statistical Institute, Plant Production Statistical. http://www.tuik.gov.tr. (Accessed on 10.08.2017). (in Turkish)

Beckman CH. 1987. The Nature of Wilt Diseases of Plants. The American Phytopathological Society, St Paul, MN.

Bell AA. 2001. Verticillium Wilt 28-31, in Eds, T.L. Kirkpatrick and C.S. Rothrock "Compendium of Cotton Diseases" Second ed. APS Pres VIII+77.

Bölek Y, Erdoğan O, Bardak A. 2011. Response of Some Cotton Genotypes to Verticillium Wilt (Verticillium dahliae Kleb.) Disease. $4^{\text {th }}$ Plant Protection Congress of Turkey, 28-30 June, Kahramanmaraş, pp.349. (in Turkish with English abstract)

Corato U, Piscioneri I, Palazzo S, Orlandini S. 2000. The Wilting of Cotton by Verticillium dahliae in Basilicata. Journal Petria, 10(2): 77-84.

Çelik İ, Soysal M, İnan Ö, Çetinkaya M. 2010. A Survey Of Cotton Wilt (Verticillium dahliae) in Antalya Region. Derim, 27(1): 18-32. (in Turkish with English abstract)

Daayf F, Nicole M, Geiger JP. 1995. Differentation of Verticillium dahliae Populations on The Basis of Vegatative Compatibility and Pathogenicity on Cotton. European Journal of Plant Pathology, 101(1): 69-79.

Erdoğan O, Sezener V, Özbek N, Bozbek T, Yavaş G, Ünay A. 2006. The Effects of Verticillium Wilt (Verticillium dahliae Kleb.) on Cotton Yield and Fiber Quality. Asian Journal of Plant Science, 5(5): 867-870. 
Erdoğan, O. 2009. Determination of Reactions of Some Cotton Breeding Lines Against Cotton Wilt Disease Caused by Verticillium dahliae Kleb. Adnan Menderes University, Journal of Faculty of Agriculture, 6(2): 9-16. (in Turkish with English abstract)

Erdoğan O, Kurt Ş. 2013. Determination of Susceptibility Against Two Different Pathotype of Verticillium dahliae Kleb. on Some Cotton Varieties. Derim, 30(1): 36-47. (in Turkish with English abstract)

Erdoğan O, Kurt Ş, Göre, ME. 2014. Studies on The Different Inoculation Methods of Verticillium Wilt Disease caused by Verticillium dahliae Kleb. in Cotton. Turkish Journal of Agricultural and Natural Sciences, 1(2): 188-193. (in Turkish with English abstract)

Erdoğan O, Bölek Y, Dündar H, Bardak A. 2015. Screening of Cotton Genotypes for Resistance to Verticillium dahliae Kleb. Under Greenhouse and Field Conditions. Romanian Agricultural Research, 32: 53-61.

Esentepe M. 1974. Investigation on Determination of the Cotton Wilt Disease Agent and its Distribution, Severity, Loss Degree and the Ecology in Adana and Antalya Provinces. Journal of Turkish Phytopathology, 3(1-2): 29-38.

Joaquim TR, Rowe RC. 1990. Reassessment of Vegetative Compatibility Relationships Among Strains of Verticillium dahliae Using Nitrate-Nonutilizing Mutants. Phytopatholgy, 80: 1160-1166.

Galanopoulo S. 2006. Cotton Wilt in Syria. CIHEAM-Options Mediterraneennes http://www.Ressources.ciheam.org./om/pdf/s14/CI01190

Galbieri R, Cia E, Fuzatto MG, Ito MF, Lüders RR, Kondo JI. 2008. Cotton Genotypes Evaluation for Resistance to Verticillium dahliae. Summa Phytopathologica, 34(3): 211-215.

Isaac I. 1967. Speciation in Verticillium. Annual Review of Phytopathology, pp. 201-222.

Göre ME, Dündar H, Erdoğan O, Ekşi İ, Sağdemir A. 2004. Investigation on the Determination of Susceptibility of Some Cotton Varieties Against Cotton Wilt Disease Caused by Verticillium dahliae Kleb. $1^{\text {th }}$ Plant Protection Congress of Turkey, 8-10 September, Samsun, pp. 161. (in Turkish with English abstract)

Göre ME, Caner ÖK, Altın N, Aydın MH, Erdoğan O, Filizer F, Büyükdöğerlioğlu A. 2009. Evaluation of Cotton Cultivars for Resistance to Pathotypes of Verticillium dahliae. Crop Protection, 28: 215-219.

Göre ME, Erdoğan O, Altın N. 2017. Searching for Resistance Sources to Verticillium Wilt of Cotton in Seedlings from Gossypium spp. Tropical Plant Pathology, 42: 28.31.

Gözcü D, Özdemir M, Günaçt1 H. 2012. Determination of Susceptibility of Some Cotton Varieties Against Wilt Disease Caused by Verticillium dahliae Kleb. in Kahramanmaras Province of Turkey. Plant Protection Bulletin, 52(2): 135-152. (in Turkish with English abstract)

Harem E. 2014. Cotton Cultivars Catalog of Turkey. Ministry of Food, Agriculture and Livestock, General Directorate of Agricultural Research and Policies, Cotton Research Institute, Publication, 74, 180 p. (in Turkish)

Karman M. 1971. General Information in Plant Protection Investigations, Evaluation and Performing of the Trials. Regional Agricultural Protection Institute, Izmir, pp. 279. (in Turkish with English abstract)
Karademir E, Karademir C, Ekinci R, Baran B, Sagir A. 2012. Effect of Verticillium dahliae Kleb. on Cotton Yield and Fiber Technological Properties. International Journal of Plant Production, 6: 387-407.

Korkmaz HY. 2005. Morphological and Pathological Properties of V. dahliae Isolates Causing Cotton Wilt Disease and Reaction of Some Cotton Varieties. MSc Thesis, Kahramanmaraş Sütçü İmam University, Graduate School of Natural and Applied Sciences, Field Crops Department, 30 pp, Kahramanmaraş. (in Turkish with English abstract)

Korolev N, Péres-Artés E, Bejarano-Alcázar J, Rodríguez-Jurado D, Katan J, Katan T, Jiménez-Díaz RM. 2001. Comparative Study of Genetic Diversity and Pathogenicity Among Populations of Verticillium dahliae from Cotton in Spain and Israel. European Journal of Plant Pathology, 107: 443-456.

Kurt S, Biçici, M. 1998. Development of V. dahliae in Cotton Plants Grown in Cukurova and Reaction of Some Cultivars to Wilt. Proceedings of the World Cotton Research Conference-2, September 6-12, Greece, 2: 919-922.

Nemli T. 2003. Cotton Disease and Control Methods. Training Seminar on Cotton, İzmir, pp. 103-111.

Onan E, Karcilıoğlu A. 1998. Pathotypes of V. dahliae from Cotton in Aegean Region and Review of Verticillium Wilt Tolerance in Nazilli 84 Cotton. Journal of Turkish Phytopathology, 27: 113120.

Pegg GF, Brady BL. 2002. Verticillium Wilts. Wallingford, UK: CABI Publishing.

Rowe RC, Powelson ML. 2002. Potato Early Dying: Management Challenges in a Changing Production Enviroment. Plant Disease, 86(11): 1184-1193.

Sağır A, Tatlı F, Gürkan, B. 1995. Studies on Diseases Growing Cotton Area in Southeastern Anatolia Region. GAP Region Symposium on Plant Protection Problems and Proposed Solutions, 27-29 April, Şanlıurfa, pp. 5-9. (in Turkish with English abstract)

Sezgin E. 1985. Cotton Wilt Disease of Control with Cultural Importance of Transactions. Periodical, 3(3): 23-31, İzmir. (in Turkish)

Steel RGD, Torrie JH, Dickey DA. 1997. Principles and Procedures of Statistics: A Biometrical Approach. 3rd edition, McGraw Hill Book Co. Inc.: 400-428, New York.

Tjamos EC, Rowe RC, Heale JB, Fravel DR. 2000. Advances in Vertcillium Research and Disease Management. APS Press Minesota, USA.

Tsror (Lahkim) L, Hazanovsy S, Mordechi-Lebiush S, Sivan S. 2001. Aggressivenes of Verticillium dahliae Isolates from Different Vegetative Compatibility Groups to Potato and Tomato. Plant Pathology, 50(4): 477-482.

USDA (United States Department of Agriculture), Foreign Agriculture service. 2016. Cotton Area, Yield, and Production. http://apps.fas.usda.gov [Accessed on 01.06.2016].

Watkins GM. 1981. Compendium of Cotton Diseases. Published by The American Phytopathological Society, 41-44.

Wu F, Wu FA. 1997. Resistant Response of The New Upland Cotton Varieties to The Defoliating Strain of V. dahliae Kleb. China-Cotton, 24(9): 11-13.

Zhengjun X, Achar PN, Benkang G. 1998. Vegetative Compatibility Groupings of Verticillium dahliae from Cotton in Mainland China. European Journal of Plant Pathology, 104: 871-876. 